Jurnal ELTIKOM, Vol. 3, No. 2, Desember 2019, hal. 45-53 ISSN 2598-3245 (Print), ISSN 2598-3288 (Online)

Tersedia online di http://eltikom.poliban.ac.id DOI : http://doi.org/10.31961/eltikom.v2i2.116

\title{
SISTEM PENUNJANG KEPUTUSAN PEMILIHAN JUARA UMUM SISWA SETIAP KEJURUAN MENGGUNAKAN METODE ANALYTICAL HIERACHY PROCESS DAN SIMPLE ADDITIVE WEIGHTING
}

\author{
Grace Gata $^{1)}$, Lusi Fajarita ${ }^{2)}$ \\ ${ }^{1,2)}$ Fakultas Teknologi Informasi Universitas Budi Luhur \\ e-mail: gatasmara@gmail.com ${ }^{1)}$, lusi.fajarita@budiluhur.ac.id²)
}

\begin{abstract}
Decision Support System is a specific information system that is intended to assist management in making decisions relating to issues that are semi-structured. This system has facilities to produce various alternatives that are interactively used by users. Vocational schools that always make improvements in improving quality so that they can produce graduates who are competent in their fields of expertise in order to be able to compete well outside the school or in the future. Therefore the school seeks to elect general champions from each vocational school to be able to review the quality of students from each vocational. And to increase motivation and interest in learning students in taking education in accordance with expertise in their fields. The purpose of this study is to implement a combination of methods of Analytical Hierarchy Process (AHP) and Simple Additive Weighting $(S A W)$ to determine the best weights and alternatives in building a general champion decision system. Three principles solve the AHP problem : the principle of compiling hierarchy, the principle of determining priorities, and the principle of measuring consistency. Basically, the AHP method solves a complex, unstructured situation, into its component parts, arranges these parts or variables in a hierarchical arrangement, gives a numerical value to the subjective considerations about the relative importance of each variable, and combines various considerations and increases reliability AHP as a decision-making tool. The basic concept of the SAW method is to find a weighted sum of performance ratings on each alternative on all attributes. The results of determining eigenvector values are Attitude Value of 0.3739, Honesty Value of 0.0808, Knowledge Value of 0.2597, Skill Value of 0952, Attendance Value of 1904 with the Consistency Index calculation of 0.0935 and Consistency Ratio of 0.0835. Conversion of the values obtained in the AHP method is an eigenvector value which is then tested by the SAW method so that a final value of 0.993 is obtained for the overall champion in each department.
\end{abstract}

Keywords: AHP, SAW, SPK, vocational school

\begin{abstract}
ABSTRAK
Sistem Penunjang Keputusan adalah suatu sistem informasi spesifik yang ditujukan untuk membantu manajemen dalam mengambil keputusan yang berkaitan dengan persoalan yang bersifat semi terstruktur. Sistem ini memiliki fasilitas untuk menghasilkan berbagai alternatif yang secara interaktif digunakan oleh pemakai. Sekolah kejuruan yang selalu melakukan perbaikan dalam meningkatkan mutu sehingga dapat menghasilkan lulusan yang kompeten dalam bidang keahliannya agar mampu bersaing dengan baik diluar sekolah maupun dimasa depan. Oleh karena itu pihak sekolah berupaya untuk melakukan pemilihan juara umum dari setiap kejuruan agar dapat meninjau kualitas siswa dari masing-masing kejuruan. Serta untuk meningkatkan motivasi dan minat belajar siswa dalam menempuh pendidikan sesuai dengan keahlian di bidangnya. Tujuan dari penelitian ini adalah mengimplementasikan kombinasi metode Analytical Hierarchy Process (AHP) dan Simple Additive Weighting (SAW) untuk menentukan bobot dan alternatif terbaik dalam membangun sistem keputusan juara umum. Tiga prinsip memecahkan persoalan AHP, yaitu prinsip menyusun hirarki, prinsip menentukan prioritas, dan prinsip mengukur konsistensi. Pada dasarnya, metode AHP tersebut memecahkan suatu situasi kompleks, tidak terstruktur, ke dalam bagian-bagian komponennya, menata bagian atau variabel tersebut dalam suatu susunan hirarki, memberi nilai numerik pada petimbangan subjektif tentang relatif pentingnya setiap variabel, dan mensintesis berbagai pertimbangan dan meningkatkan keandalan AHP sebagai alat pengambilan keputusan. Konsep dasar metode SAW adalah mencari penjumlahan terbobot dari rating kinerja setiap alternatif pada semua atribut. Hasil penentuan nilai eigenvector yaitu untuk Nilai Sikap sebesar 0,3739, Nilai Kejujuran sebesar 0,0808, Nilai Pengetahuan sebesar 0,2597, Nilai Keterampilan sebesar 0952, Nilai Absensi sebesar 1904 dengan perhitungan Consistency Index yang didapat sebesar 0,0935 dan Consistensy Ratio sebesar 0,0835.
\end{abstract}


Konversi dari nilai yang didapatkan dalam metode AHP yaitu berupa nilai eigenvector yang kemudian diujikan dengan metode SAW sehingga didapatkan nilai akhir sebesar 0,993 untuk juara umum setiap jurusan.

Kata Kunci: AHP, SAW, SPK, sekolah kejuruan

\section{Pendahuluan}

$\mathrm{S}$ EKOLAH kejuruan memiliki fokus pada pengembangan diri dan kompetensi kejuruan. Tak jarang, pihak sekolah akan melakukan berbagai hal positif untuk meninjau kualitas siswa dari masing-masing kejuruan seperti dengan melakukan pemilihan juara umum dari setiap kejuruan. Adapun siswa yang menyandang gelar juara tersebut akan menerima penghargaan berupa beasiswa yaitu bebas biaya SPP (Sumbangan Pembinaan Pendidikan) di semester selanjutnya. Namun seringkali terdapat kendala saat menentukan juara umum setiap jurusan, seperti potensi penilaian secara subjektivitas apabila hasil akhir dari penilaian memiliki nilai yang sama. Hal ini disebabkan karena belum adanya pembobotan terhadap setiap kriteria yang dinilai.

Dengan adanya penilaian yang masih terpengaruhi secara subjektivitas maka seringkali mengakibatkan pemahaman serta pola pikir siswa yang beranggapan bahwa penghargaan juara umum diberikan karena siswa dapat membangun komunikasi yang baik secara berlebihan antar guru sehingga menjadi nilai tambah untuk menunjang keberhasilan pada prestasi siswa. Oleh karena itu penerapan sistem informasi penunjang keputusan berbasis komputer dibutuhkan untuk untuk mencapai target atau aksi tertentu yang harus dilakukan [1]. Tentunya juga didukung dengan parameter atau kriteria-kriteria apa saja yang akan dinilai [2].

Metode yang digunakan dalam membangun sistem ini adalah kombinasi antara metode Analytical Hierarchy Process (AHP) dan metode Simple Additive Weighting (SAW). Metode AHP dapat digunakan untuk mengolah data dari satu responden ahli [3]. Dan metode Simple Additive Weighting digunakan untuk mencari penjumlahan terbobot dari rating kinerja pada setiap alternatif pada semua atribut [4].

Alasan memilih metode AHP karena belum adanya pembobotan untuk setiap kriteria penilaian dan alasan penulis menggunakan metode SAW karena metode ini dapat melakukan perhitungan yang menghasilkan nilai terbesar sehingga akan terpilih sebagai alternatif terbaik. Dengan dibangunnya sistem penunjang keputusan ini dapat membantu Wakasek Bidang Kurikulum sekolah sekolah kejuruan dalam memecahkan uraian permasalahan terkait pemilihan juara umum disetiap kejuruan. Pada penelitian ini, terdapat lima kriteria yang digunakan untuk penilaian secara objektif, yaitu : Nilai Sikap, Nilai Kejuruan, Nilai Pengetahuan, Nilai Keterampilan, dan Absensi. Selain itu proses pemilihan juara umum pada sekolah kejuruan yaitu berdasarkan nilai raport akhir semester genap dan nilai absensi siswa dalam pengambilan keputusan untuk menentukan juara umum dari setiap kejuruan. Sistem penunjang keputusan ini diperlukan agar keputusan yang diperoleh lebih cepat, tepat, dan efektif dalam menentukan juara umum setiap jurusan, serta dapat menghasilkan keputusan secara objektif.

\section{STUDI LITERATUR}

Sistem Penunjang Keputusan sebagai suatu informasi berbasis komputer yang menghasilkan berbagai alternatif keputusan untuk membantu manajemen dalam menangani berbagai permasalahan yang terstruktur maupun tidak terstruktur dengan menggunakan data dan model [5]. Dalam sebuah sistem pendukung terdapat beberapa jenis solusi pemecahan masalah diataranya yaitu: Multi Attribute Decision Making (MADM) seperti: Metode Simple Additive Weighting (SAW), Metode Weight Product (WP), Metode Analythical Hierarchy Process (AHP), Metode Topsis dan Lain-lain. Kemudian Metode Multi Criteria Decision Making (MCDM) seperti: Metode Promethee, Metode Electre, Metode Oreste, Metode Entropi dan Lain-lain. Selain terdapat juga Metode Multi Factor Evaluation Process (MFEP), Metode Multi Attribute Utility Theory (MAUT) serta Metode FMADM (Fuzzy Multi Attribute Decision Making) yang terdiri dari F-AHP, F-SAW dan Lain-lain.

\section{Metode Analythical Hierarchy Process (AHP)}

Adalah metode pengambilan keputusan dengan cara memecah suatu masalah yang kompleks dan tidak terstruktur ke dalam kelompok-kelompok dan mengaturnya ke dalam suatu hirarki [6]. 
Cara menguji metode AHP yaitu dengan menghitung nilai CI (Consistency Index) dan CR (Consistency Ratio).

Rumus menghitung Consistency Index :

$$
C I=\frac{\bar{x}-n}{n-1}
$$

Penjelasan Persamaan 1 :

$\mathrm{CI}=$ Consistency Index

$\bar{x}=$ nilai rata-rata dari consistency vector

$\mathrm{n} \quad=$ Jumlah penilai

Rumus menghitung Consistency Ratio :

$$
C R=\frac{C I}{R I}
$$

Penjelasan Persamaan 2 :

$$
\begin{aligned}
\mathrm{CR} & =\text { Consistency Ratio } \\
\mathrm{CI} & =\text { Consistency Index } \\
\mathrm{RI} & =\text { Random Index }
\end{aligned}
$$

Jika hasil dari $\mathrm{CR}<0,1$, maka nilai dari matriks yang berpasangan adalah konsisten, jika $>0,1$ maka nilai tersebut tidak konsisten.

Random Index (RI) (Tabel I) merupakan suatu ukuran yang dipakai untuk menghitung rasio kekonsistenan (CR) dari penilaian terhadap matriks perbandingan dari seorang responden. Random Index dikeluarkan oleh Oak Ridge Laboratory dari matriks berorde 1 sampai 15 dengan menggunakan sample berukuran 100. Nilai RI ini akan digunakan untuk menghitung Consistency Ratio(CR) setiap kriteria pada metode AHP, dimana $\mathrm{N}$ adalah jumlah kriteria yang digunakan dalam penilaian. Nilai akhir CR yang disarankan harus lebih kecil atau sama dengan 0,1 . Sehingga nilai tersebut mempunyai tingkat konsistensi yang baik dan dapat dipertanggungjawabkan.

TABEL I

NILAI RANDOM INDEX (OARKRIDGE LABORATORY)

\begin{tabular}{ccccccccccc}
\hline \hline $\mathrm{N}$ & 1 & 2 & 3 & 4 & 5 & 6 & 7 & 8 & 9 & 10 \\
\hline $\mathrm{R}$ & 0,00 & 0,00 & 0,58 & 0,90 & 1,12 & 1,24 & 1,32 & 1,41 & 1,45 & 1,49 \\
\hline \hline
\end{tabular}

\section{Metode Simple Additive Weighting (SAW)}

Menurut Fishburn dan MacCrimmon mengemukakan bahwa Metode Simple Additive Weight (SAW) sering juga dikenal dengan istilah metode penjumlahan terbobot [7]. Konsep dasar metode Simple Additive Weight (SAW) adalah mencari penjumlahan terbobot dari rating kinerja pada setiap alternatif pada semua atribut [8]. SAW juga membutuhkan normalisasi matriks keputusan (X) ke skala perbandingan dari semua klasifikasi alternatif [9].

Rij

$=\left\{\begin{array}{l}\frac{X i j}{M a x X i j} \text { (jika j adalah atribut keuntungan atau benefit) } \\ \frac{\text { Min Xij }}{X i j}(j i k a j \text { adalah atribut biaya atau cost) }\end{array}\right.$

Penjelasan Persamaan 3 :

Rij = Rating kinerja ternormalisasi

Maxij = Nilai maksimum dari setiap baris dan kolom

Minij = Nilai minimum dari setiap baris dan kolom

$\mathrm{Xij}=$ Baris dan kolom dari matriks Dengan $\mathrm{Ri} \mathrm{j}$ adalah rating kinerja ternormalisasi dari alternatif Ai pada atribut $\mathrm{Cj} ; \mathrm{i}=1,2, \ldots \mathrm{m}$ dan $\mathrm{j}=1,2, \ldots, \mathrm{n}$.

Benefit $=$ Jika nilai terbesar terbaik

Cost $=$ Jika nilai terkecil terbaik 


$$
V i=\sum_{J=i}^{n} W_{j} R_{i j}
$$

Penjelasan Persamaan 4 :

Nilai Vi yang lebih besar mengindikasikan bahwa alternatif Ai lebih terpilih.

Penjelasan persamaan(4):

Vi = Nilai akhir dari alternatif

$\mathrm{Wi}=$ Bobot yang telah ditentukan

Rij $=$ Normalisasi matriks

\section{MeTODE PENELITIAN}

Pemikiran yang sistematis dalam penelitian adalah metode yang akan digunakan dalam membangun sistem penunjang keputusan ini adalah kombinasi dari metode Analytical Hierarchy Process (AHP) untuk melakukan pembobotan dan Simple Additive Weighting (SAW) untuk melakukan perankingan.

\section{A. Strategi Penelitian}

Penelitian ini menggunakan tahapan dalam fase proses pengambilan keputusan sebagai berikut:

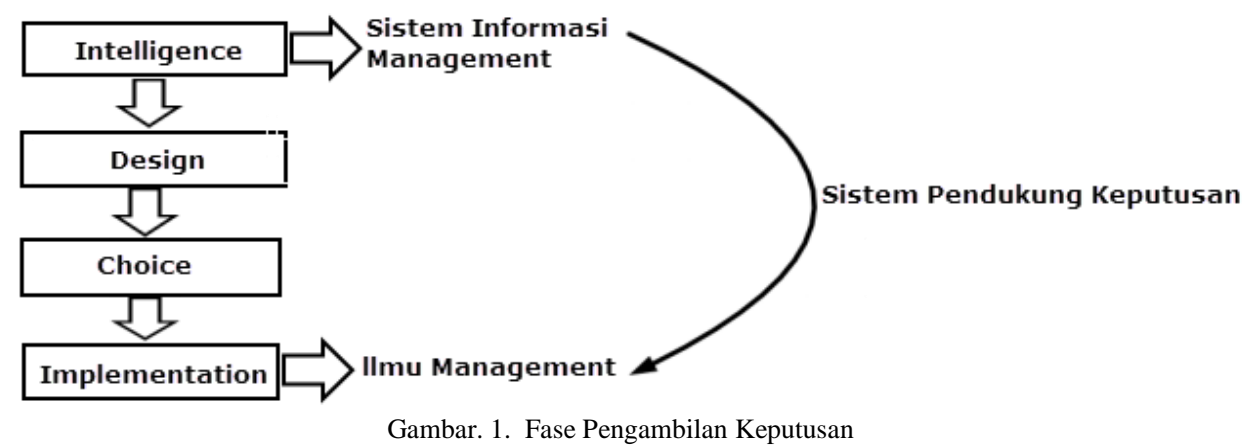

Pola pikir tersebut (Gambar 1) memberikan gambaran bahwa pada fase Intelligence merupakan tahapan proses penelusuran dan pendeteksian dari ruang lingkup problematika secara proses pengenalan masalah. Data masukan diperoleh, diproses dan diuji dalam rangka mengidentifikasi masalah, Fase Design merupakan tahapan proses menemukan, mengembangkan dan menganalisis alternatif tindakan yang bisa dilakukan, meliputi menguji kelayakan solusi, Fase Choice merupakan tahapan dilakukan proses pemilihan diantara berbagai alternatif tindakan yang mungkin dijalankan. Hasil pemilihan tersebut kemudian diimplementasikan dalam proses pengambilan keputusan, dan yang terakhir adalah Fase Implementation merupakan implementasi suatu solusi yang diusulkan untuk suatu masalah adalah inisiasi terhadap hal baru atau pengenalan terhadap perubahan. Definisi implementasi sedikit rumit karena implementasi merupakan sebuah proses yang panjang dan melibatkan batasan-batasan yang tidak jelas.

\section{Langkah Riset Operasional}

Kerangka riset operasional dalam penelitian ini berawal dari perumusan masalah dengan melakukan proses analisis dengan cara studi pustaka dan studi lapangan. Studi pustaka yang dilakukannya yaitu dengan mencari studi kasus pengambilan keputusan yang mempunyai masalah yang sama tetapi dengan berbagai metodologi. Proses pencarian berasal dari jurnal-jurnal. Kemudian studi lapangan dengan melakukan kunjungan ke sekolah kejuruan untuk mewawancarai kepala sekolah dan guru. Identifikasi masalah, Langkah selanjutnya pengumpulan data. Setelah tahap pengumpulan data, maka langkah selanjutnya adalah desain, lalu dilanjutkan dengan tahap implementasi. Pada tahap ini dilakukan proses perankingan yang akan menentukan alternatif secara optimal. Data Alternatif berasal dari siswa yang akan dipilih menjadi juara umum setiap kejuruan dari tiga kandidat masing-masing kelas setiap kejuruan berdasarkan kriteria yang telah ditetapkan yaitu : Nilai Sikap, Nilai Pengetahuan, Nilai Keterampilan, Nilai Kejuruan, dan Absensi. 


\section{IV.HASIL DAN PEMBAHASAN}

\section{A. Pengolahan Data Kriteria dengan Metode Analytical Hierarchy Process (AHP)}

Metode AHP ini digunakan untuk menentukan bobot dari kriteria dan sib kriteria penilaian. Data yang digunakan dalam penelitian ini berasal dari siswa yang akan dipilih menjadi juara umum setiap kejuruan dari tiga kandidat masing-masing kelas setiap kejuruan. Adapun parameter yang akan dihitung adalah nilai kriteria dan sub kriteria. Penilaian kriteria terdiri dari : Nilai Sikap, Nilai Pengetahuan, Nilai Keterampilan, Nilai Kejuruan, dan Absensi. Penilaian sub kriteria dari absensi antara lain : sakit, izin dan alpha. Berdasarkan kuesioner yang telah diajukan kepada responden maka didapat tabel matriks perbandingan setiap kriteria. Hasil ini diperoleh berdasarkan tingkat kepentingan dari masing-masing kriteria (Tabel II):

TABEL II

PERBANDINGAN KEPENTINGAN ANTAR KRITERIA

\begin{tabular}{lccccc}
\hline \hline \multicolumn{1}{c}{ Kriteria } & Nilai Sikap & Nilai Kejuruan & Nilai Pengetahuan & Nilai Keterampilan & Absensi \\
\hline Nilai Sikap & $1 / 1$ & $5 / 1$ & $3 / 1$ & $2 / 1$ & $1 / 1$ \\
Nilai Kejujuran & $1 / 5$ & $1 / 1$ & $1 / 3$ & $1 / 1$ & $1 / 2$ \\
Nilai Pengetahuan & $1 / 3$ & $3 / 1$ & $1 / 1$ & $4 / 1$ & $2 / 1$ \\
Nilai Keterampilan & $1 / 2$ & $1 / 1$ & $1 / 4$ & $1 / 1$ & $1 / 2$ \\
Absensi & $1 / 1$ & $2 / 1$ & $1 / 2$ & $2 / 1$ & $1 / 1$ \\
\hline \hline
\end{tabular}

Langkah 1, menjabarkan matriks diatas kedalam bentuk decimal (Tabel III):

TABEL III

MATRIKS BILANGAN DECIMAL

\begin{tabular}{lccccc}
\hline \multicolumn{1}{c}{ Kriteria } & Nilai Sikap & Nilai Kejuruan & Nilai Pengetahuan & Nilai Keterampilan & Absensi \\
\hline Nilai Sikap & 1,0000 & 5,0000 & 3,0000 & 2,0000 & 1,0000 \\
Nilai Kejujuran & 0,2000 & 1,0000 & 0,3333 & 1,0000 & 0,5000 \\
Nilai Pengetahuan & 0,3333 & 3,0000 & 1,0000 & 4,0000 & 2,0000 \\
Nilai Keterampilan & 0,5000 & 1,0000 & 0,2500 & 1,0000 & 0,5000 \\
Absensi & 1,0000 & 0,2000 & 0,5000 & 2,0000 & 1,0000 \\
\hline \hline
\end{tabular}

Contoh data pada baris kedua kolom pertama : angka 0,2000 diperoleh dari 1/5 (mengacu pada Tabel II).

Langkah ke 2, mengkalikan matriks pada Tabel III dengan dirinya sendiri (iterasi 1) (Tabel IV):

TABEL IV

HASIL PERKALIAN MATRIKS

\begin{tabular}{lccccc}
\hline \hline \multicolumn{1}{c}{ Kriteria } & Nilai Sikap & Nilai Kejuruan & Nilai Pengetahuan & Nilai Keterampilan & Absensi \\
\hline Nilai Sikap & 4,9999 & 23,0000 & 8,6665 & 23,000 & 11,5000 \\
Nilai Kejujuran & 1,5111 & 4,9999 & 1,7666 & 4,7332 & 2,3666 \\
Nilai Pengetahuan & 5,2666 & 15,6665 & 4,9998 & 15,6666 & 7,8333 \\
Nilai Keterampilan & 1,7833 & 6,2500 & 2,5833 & 5,0000 & 2,5000 \\
Absensi & 3,5667 & 12,5000 & 5,1666 & 10,0000 & 5,0000 \\
\hline \hline
\end{tabular}

Langkah ke 3, menjumlahkan setiap baris matriks pada tabel IV sehingga menghasilkan data berikut: Nilai Sikap $=71,1664$, Nilai Kejujuran $=15,3774$, Nilai Pengetahuan $=49,4328$, Nilai Keterampilan $=$ 18,1166 dan Nilai Absensi $=36,2333$. Sehingga total keseluruhan dari kriteria tersebut menjadi 190,3265 .

Langkah ke 4, menentukan nilai eigenvector dengan cara membagi tiap-tiap jumlah baris pada matriks dengan total baris:
1) Nilai Sikap
$=71,1664 \div 190,3265=0,3739$
2) Nilai Kejujuran
$=15,3774 \div 190,3265=0,0808$
3) Nilai Pengetahuan $=49,4328 \div 190,3265=0,2597$
4) Nilai Keterampilan $=18,1166 \div 190,3265=0,0952$
5) Nilai Absensi $=36,2333 \div 190,3265=0,1904$

Hasil dari eigenvector ini yang akan digunakan didalam perhitungan SAW. 


\section{B. Pengujian Bobot Kriteria dengan Analytical Hierarchy Process (AHP)}

Langkah 1, mengkalikan nilai pada matriks awal (Tabel III) dengan nilai eigenvector sehingga menghasilkan Nilai Sikap $=1,9378$, Nilai Kejuruan $=0,4325$, Nilai Pengetahuan $=1,3883, \quad$ Nilai Keterampilan $=0,5231$, dan Nilai Absensi $=1,0462$.

Langkah 2, menghitung consistency vector dengan cara membagi hasil pada langkah 1 dengan dengan nilai eigenvector sehingga menghasilkan : Nilai Sikap $=5,1827$, Nilai Kejuruan $=5,3527$, Nilai Pengetahuan $=5,3458$, Nilai Keterampilan $=5,4947$ dan Nilai Absensi $=5,4947$.

Langkah 3, menentukan nilai rata-rata consistency vector dengan cara membagi keseluruhan nilai consistency vector dengan jumlah kriteria, sehingga menghasilkan nilai akhir $=5,3741$.

Langkah 4, menghitung CI (Consistency Index) dan CR (Consistency Ratio) :

$$
\mathrm{CI}=(5,3741-5) \div(5-1)=0,0935
$$

Untuk menghitung CR dibutuhkan nilai dari random index (Tabel I) $: C R=\frac{0,0935}{1,12}=0,0835$

Hasil perhitungan $\mathrm{CI}$ dan $\mathrm{CR}$ adalah $<0.1$, sehingga dapat disimpulkan bahwa nilai dari matriks yang berpasangan adalah konsisten. Untuk pengujian data sub kriteria absensi (sakit, izin dan alpha) menggunakan langkah yang sama seperti menghitung bobot dari kriteria dan di uji sehingga menghasilkan nilai akhir yang konsisten.

\section{Pengolahan Data dengan Metode Simple Additive Weighting (SAW) Untuk Perankingan}

Sebelum melakukan perhitungan dengan metode SAW, terdapat proses konversi nilai eigenvector kriteria dan sub kriteria kedalam format bobot prosentase. Total bobot ini jika dijumlahkan seharusnya tidak lebih dari 100\% (Tabel V). Serta konversi nilai absensi (Tabel VI).

TABEL V

BOBOT KRITERIA DAN SUB KRITERIA

\begin{tabular}{|c|c|c|c|c|c|}
\hline Kriteria & $\begin{array}{c}\text { Nilai } \\
\text { Egienvector }\end{array}$ & Bobot & $\begin{array}{c}\text { Sub } \\
\text { Kriteria }\end{array}$ & $\begin{array}{c}\text { Nilai } \\
\text { Eigenvector }\end{array}$ & Bobot \\
\hline \multirow{5}{*}{$\begin{array}{l}\text { Nilai Sikap (benefit) } \\
\text { Nilai Kejujuran (benefit) } \\
\text { Nilai Pengetahuan (benefit) } \\
\text { Nilai Keterampilan } \\
\text { (benefit) } \\
\text { Absensi (cost) }\end{array}$} & 0,3739 & $37,39 \%$ & Sakit & 0,6607 & $66,07 \%$ \\
\hline & 0,0808 & $8,08 \%$ & Izin & 0,2620 & $26,2 \%$ \\
\hline & 0,2569 & $25,97 \%$ & Alpha & 0,0773 & $7,73 \%$ \\
\hline & 0,0952 & $9,52 \%$ & & & \\
\hline & 0,1904 & $19,04 \%$ & \multirow{2}{*}{\multicolumn{2}{|c|}{$\begin{array}{r}\text { Total Bobot Sub } \\
\text { Kriteria }\end{array}$}} & \\
\hline \multicolumn{2}{|c|}{ Total Bobot Kriteria } & $100 \%$ & & & $100 \%$ \\
\hline
\end{tabular}

TABEL VI

\begin{tabular}{cc}
\multicolumn{2}{c}{ KONVERSI NILAI ABSENSI } \\
\hline \hline Sebelum & Setelah \\
Konversi & Konversi \\
\hline 0-1 hari & 4 \\
2-3 hari & 3 \\
4-5 hari & 2 \\
6-7 hari & 1 \\
\hline \hline
\end{tabular}

Data sample berasal dari dua kelas kejuruan yaitu Kelas X TKJ dan Kelas X Akuntasi (Tabel VII) :

TABEL VII

NiLAi ALTERNATIF KELAS X

\begin{tabular}{|c|c|c|c|c|c|c|c|c|}
\hline \multirow{3}{*}{ Alternatif } & \multirow{3}{*}{ Kejuruan } & \multicolumn{7}{|c|}{ Kriteria } \\
\hline & & \multirow{2}{*}{ Nil.Sikap } & \multirow{2}{*}{ Nil. Kejuruan } & \multirow{2}{*}{ Nil. Pengetahuan } & \multirow{2}{*}{ Nil. Keterampilan } & \multicolumn{3}{|c|}{ Absensi } \\
\hline & & & & & & Sakit & Izin & Alpha \\
\hline Rizky & TKJ & 4 & 589 & 577 & 404 & 0 & 0 & 0 \\
\hline Pijar & TKJ & 4 & 593 & 569 & 398 & 1 & 3 & 0 \\
\hline Fachrul & TKJ & 4 & 578 & 563 & 416 & 1 & 0 & 0 \\
\hline Maya & Akuntansi & 4 & 528 & 595 & 404 & 2 & 0 & 0 \\
\hline Siti Aliyah & Akuntansi & 4 & 530 & 600 & 428 & 1 & 1 & 0 \\
\hline Marwah & Akuntansi & 4 & 524 & 596 & 423 & 0 & 2 & 1 \\
\hline Ilham & Akuntansi & 4 & 550 & 615 & 440 & 1 & 0 & 1 \\
\hline Munawar & Akuntansi & 4 & 550 & 590 & 419 & 0 & 0 & 0 \\
\hline Nurwati & Akuntansi & 4 & 545 & 610 & 416 & 0 & 2 & 0 \\
\hline
\end{tabular}


Langkah 1, mengubah data pada Tabel VII menjadi nilai matriks dengan mengacu pada (Persamaan 3) dan memperhatikan kriteria benefit maupun cost :

TABEL VIII

NILAI MATRIKS NORMALISASI KRITERIA KELAS X

\begin{tabular}{lcccccc}
\hline \hline \multirow{2}{*}{ Alternatif } & Kejuruan & Nil.Sikap & Nil. Kejuruan & Nil. Pengetahuan & Nil. Keterampilan & Absensi \\
\hline Rizky & TKJ & 1,0000 & 0,9933 & 1,0000 & 0,9712 & 0,9345 \\
Pijar & TKJ & 1,0000 & 1,0000 & 0,9861 & 0,9567 & 1,0000 \\
Fachrul & TKJ & 1,0000 & 0,9474 & 0,9757 & 1,000 & 0,9345 \\
Maya & Akuntansi & 1,0000 & 0,9600 & 0,9675 & 0,9182 & 0,9345 \\
Siti Aliyah & Akuntansi & 1,0000 & 0,9636 & 0,9756 & 0,9727 & 0,7693 \\
Marwah & Akuntansi & 1,0000 & 0,9527 & 0,9691 & 0,9614 & 0,8348 \\
Ilham & Akuntansi & 1,0000 & 1,0000 & 1,0000 & 1,0000 & 0,7693 \\
Munawar & Akuntansi & 1,0000 & 1,0000 & 0,9593 & 0,9523 & 0,7693 \\
Nurwati & Akuntansi & 1,0000 & 0,9909 & 0,9919 & 0,9455 & 0,8348 \\
\hline \hline
\end{tabular}

Langkah 2, mengkalikan setiap baris data nilai kriteria yang ada pada Tabel VIII dengan nilai eigenvector:

TABEL IX

\begin{tabular}{lcc}
\multicolumn{3}{c}{ AlternATIF TERPILIH MENJADI JUARA UMUM } \\
\hline \hline Alternatif & Kejuruan & Nilai Akhir \\
\hline Rizky & TKJ & 0,9843 \\
Pijar & TKJ & 0,9923 \\
Fachrul & TKJ & 0,9792 \\
Maya & Akuntansi & 0,9681 \\
Siti Aliyah & Akuntansi & 0,9443 \\
Marwah & Akuntansi & 0,9530 \\
Ilham & Akuntansi & 0,9561 \\
Munawar & Akuntansi & 0,9410 \\
Nurwati & Akuntansi & 0,9605 \\
\hline \hline
\end{tabular}

Penjelasan Tabel IX , nilai akhir Rizky diperoleh dari :

$\{(1,0000 \times 0,3739)+(1,0000 \times 0,0808)+(0,9861 \times 0,2597)+(0,9567 \times 0,0952)+(1,0000 \times 0,1904)\}=0,9923$. Berdasarkan perhitungaan pada Tabel IX diperoleh data kandidat juara umum setiap jurusan per angkatan adalah: Pijar dari kelas X TKJ dan Maya dari kelas X Akuntasi.

\section{Perancangan Basis Data}

Bentuk model data dalam penelitian ini berupa Class Diagram. Class diagram merupakan salah satu bentuk UML(Unified Modelaing Language) berupa spesifikasi yang akan menghasilkan objek dan merupakan inti dari pengembangan dan desain berorientasi objek [10]. Objek-objek ini merupakan tabel atau file yang digunakan untuk menyimpan data ke dalam database. (Gambar 2).

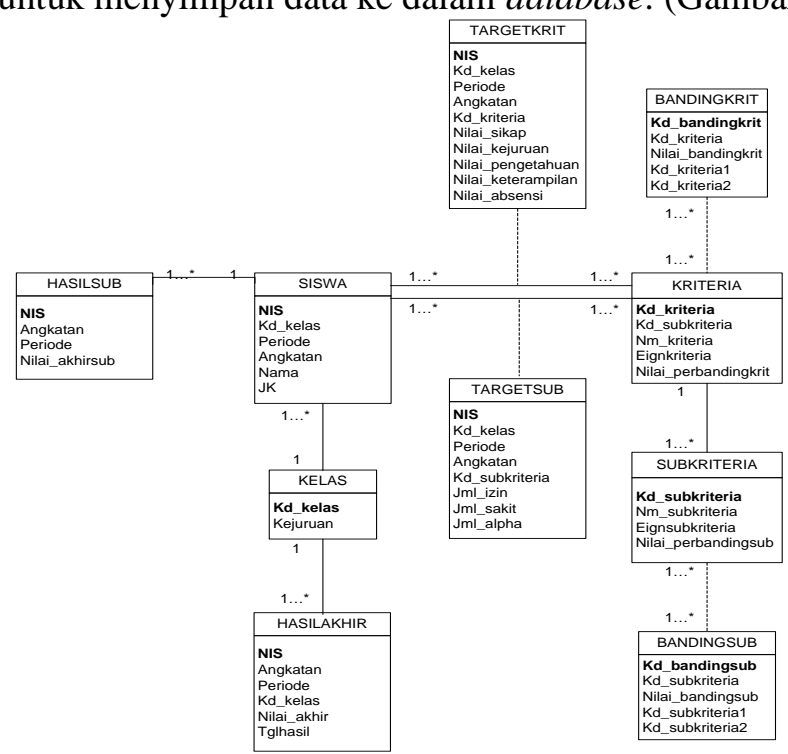

Gambar. 2. Class Diagram Sistem Pengambilan Keputusan 


\section{E. Rancangan Antar Muka}

Gambar 3, merupakan rancangan antarmuka untuk mengolah nilai perbandingan antar kriteria yang dikonversi kedalam bentuk matriks. Serta menampilkan hasil akhirnya berupa nilai eigenvector.

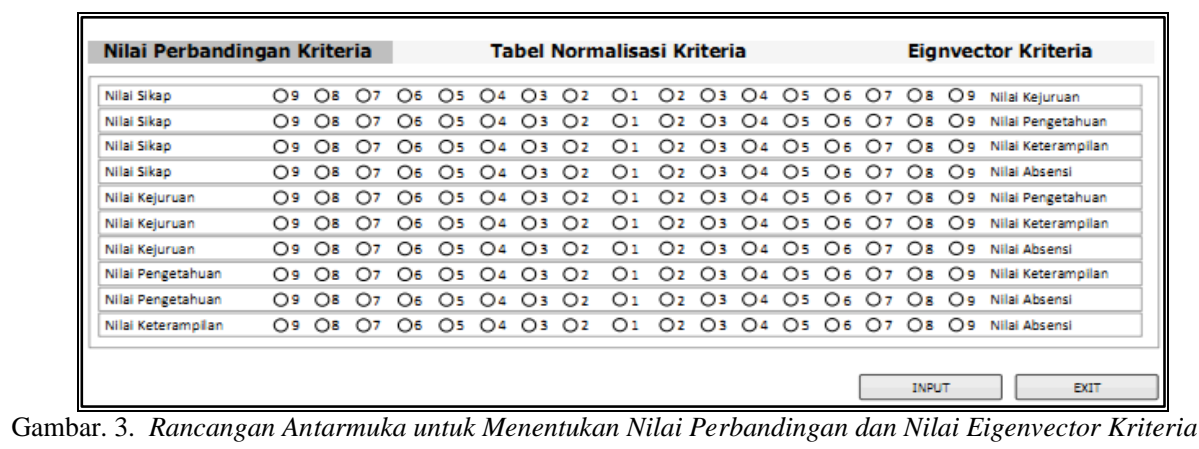

Gambar 4, merupakan rancangan antarmuka untuk mengolah data nilai kriteria yang dikonversi kedalam bentuk matriks. Serta menampilkan data siswa yang masuk ke dalam kandidat sebagai juara umum.

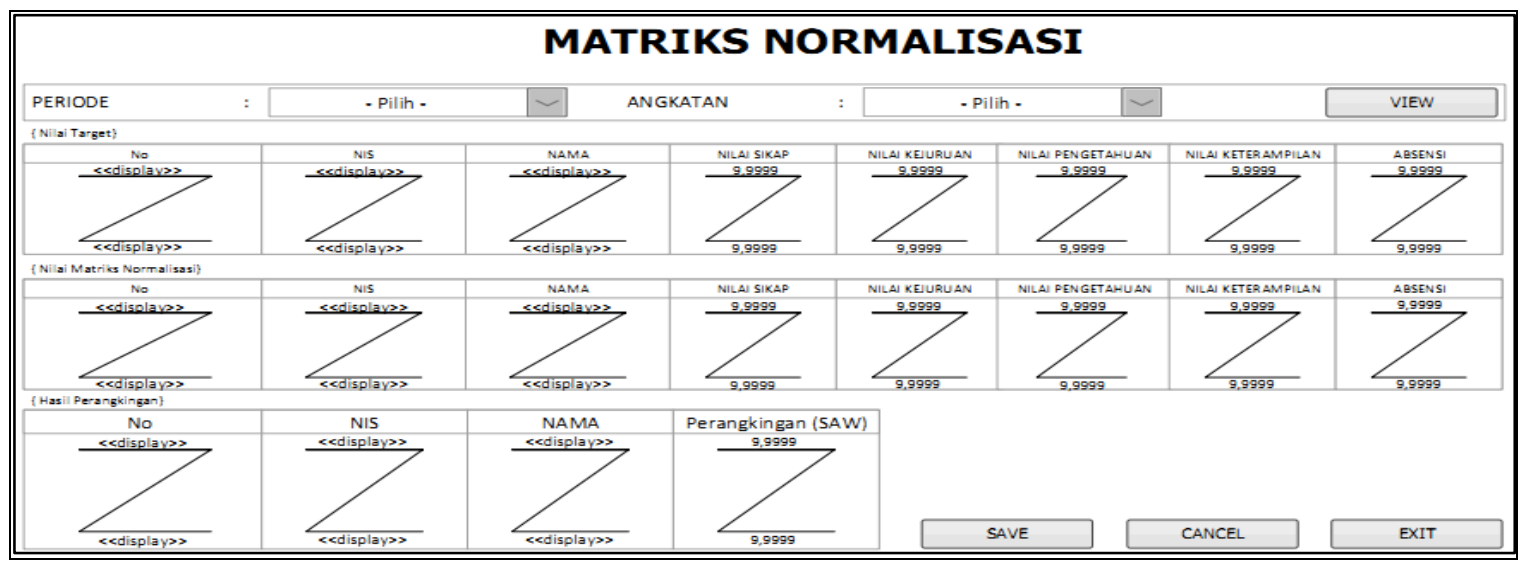

Gambar. 4. Rancangan Antarmuka untuk Perhitungan Matriks Normalisasi Data Kriteria

\section{KESIMPULAN}

Penggunaan metode Analytical Hierarchy Process (AHP) sebagai penentuan bobot dari kriteria dan subkriteria yang digunakan untuk acuan penilaian siswa per kriteria dan per subkriteria menghasilkan nilai rasio yang konsisten karena tidak lebih dari 0,1. Sedangkan metode Simple Additive Weighting (SAW) dalam menentukan peringkat atau perankingan, menghasilkan nilai akhir yang objektif sesuai dengan nilai eigenvector masing-masing kriteria dan sub kriteria yang sudah ditentukan, sehingga proses penilaian juara umum terhindar dari adanya penilaian yang subjektif.

\section{DAFTAR PUSTAKA}

[1] Nofriansyah., Dicky dan Sarjono D, "Bab I Pendahuluan", dalam Multi Criteria Decision Making (NCDM) Pada Sistem Pendukung Keputusan, Edisi Ke 1, Yogyakarta, Indonesia, 2017, Bab I, Hal. 6.

[2] Asnawati., Indra Kanedi, "Sistem Pendukung Keputusan Kenaikan Pangkat Karyawan Perseroan Terbatas Pelayaran Kumafa Lagun Marina Bengkulu", Jurnal Media Infotama, Vol.8, No. 1, hal. 118-137, Februari, 2012.

[3] Sulistiyani, Endang., dkk, "Implementasi Metode Analytical Hierarchy Process (AHP) Sebagai Solusi Alternatif Dalam Pemilihan Supplier Bahan Baku Apel Di PT. Mannasatria Kusumajaya”, Technology Science and Engineering Journal, Vol.1, No. 2, hal. 87-101, Juni, 2017.

[4] Situmorang, Harold, "Sistem Pendukung Keputusan Pemilihan Calon Peserta Olimpiade Sains Tingkat Kabupaten Langkat Pada Madrasah Aliyah Negeri (MAN) 2 Tanjung Pura Denganmenggunakan Metode Simple Additive Weighting (SAW)”, TIMES, Vol. 4, No. 2, hal. 24-30, Desember, 2015.

[5] Faisal dan Silvester Dian HP, "Sistem Penunjang Keputusan Pemilihan Sekolah Menengah Kejuruan Teknik Komputer Dan Jaringan Yang Terfavorit Dengan Menggunakan Multi-Criteria Decision Making”, Jurnal Teknologi Informasi dan Ilmu Komputer (JTIIK), Vol.2, No. 1, hal. 11-19, April, 2015. 
[6] Ardiansyah, M Opy, dan Kristian Siregar, “. Implementasi Sistem Pendukung Keputusan Pemilihan Siswa Berprestasi Menggunakan Metode Analitic Hierarchy Process (AHP) pada SMK Negeri Rundeng”, Pelita Informatika Budi Darma, Vol. 15, No. 1, hal. 12-18, Oktober, 2016.

[7] Hasibuan, Wilda Rina, "Sistem Pendukung Keputusan Dalam Menentukan Jenis Tanaman Pada Lahan Pertanian Dengan Menggunakan Metode Simple Additive Weighting (SAW)", Agrium, Vol. 20, No. 2, hal. 157-162, Oktober, 2016.

[8] Frieyadie, "Penerapan Metode Simple Additive Weight (SAW) Dalam Sistem Pendukung Keputusan Promosi Kenaikan Jabatan", Jurnal Pilar Nusa Mandiri, Vol. 12, No. 1, hal. 37-45, Maret, 2016.

[9] Supiadi, Asmadi., dkk, "Sistem Pendukung Keputusan Menentukan Siswa Terbaik Menggunakan Metode Simple Additive Weighting (SAW)", Jurnal ELTIKOM, Vol. 1, No. 1, hal. 26-33, Juni, 2017.

[10] Isa, Indra Griha., dan George Pri Hartawan, "Perancangan Aplikasi Koperasi Simpan Pinjam Berbasis Web (Studi Kasus Koperasi Mitra Setia)", Jurnal Ilmiah Ilmu Ekonomi, Vol. 5, No. 10, hal. 139-151, Maret, 2017. 